\title{
A TRANSIÇÃO PARA O CASAMENTO EM CASAIS COABITANTES E EM CASAIS NÃO-COABITANTES ${ }^{*}$
}

\author{
THE TRANSITION TO MARRIAGE IN COHABITING AND \\ NON-COHABITING COUPLES
}

Clarissa C. Menezes**

Rita de C. S. Lopes

\begin{abstract}
Menezes CC, Lopes RCS. A Transição para o casamento em casais coabitantes e em casais nãocoabitantes. Rev Bras Crescimento Desenvolv Hum 2007; 17(1):52-63.

Resumo: Este estudo objetivou analisar como os casais coabitantes e os não-coabitantes passam pela transição para o casamento. Participaram quatro casais adultos, sendo dois coabitantes e dois não-coabitantes. Abrangeu quatro etapas: o semestre anterior ao casamento e o primeiro, o sexto e o décimo segundo mês de casamento. As entrevistas foram realizadas com cada indivíduo, submetidas à análise de conteúdo qualitativa e agrupadas em três eixos temáticos: $a$ individualidade e a conjugalidade; a cerimônia de casamento e a avaliação da própria relação; e a relação com a família de origem. Os resultados revelaram uma tendência à polarização e à estabilidade quanto à individualidade e à conjugalidade e à relação com as famílias de origem, sendo que não houve diferença entre casais coabitantes e não-coabitantes nestes aspectos. Sobre a avaliação da própria relação e a cerimônia de casamento, houve diferenças entre coabitantes e não-coabitantes.
\end{abstract}

Palavras chave: Casamento. Coabitantes. Não-coabitantes. Conjugalidade. Individualidade.

\section{INTRODUÇÃO}

Este estudo se propõe a investigar a transição para o casamento a partir da visão Sistêmica, que vem se desenvolvendo desde os anos cinquienta e parte do pressuposto de que o ser humano não está isolado, mas faz parte e sofre influências constantes do meio social em que está inserido. Sua experiência é determinada por sua interação constante com o ambiente. Neste sentido, o meio familiar, o primeiro com o qual os indivíduos têm contato, tornou-se o foco central desta abordagem na compreensão do desenvolvimento e do comportamento humano. O casamento, por sua vez, ao delimitar o inicio das famílias, vem sendo abordado por alguns pesquisadores. Entretanto, a transição para o casamento e suas peculiaridades como fase inicial do desenvolvimento do casal têm sido relativamente pouco consideradas pelos teóricos que se ocupam em estudar os casais e as famílias. Acredita-se que o período que compreende os meses anteriores e o primeiro ano de relacionamento conjugal é bastante relevante e especial. Neste período, o casal depara-se com uma mudança real de status social, aparece a necessidade de administração da conjugalidade com a individualidade; as expectativas e as motivações anteriores são postas em prática (ou não); e há a necessidade de reorganizar os relacionamentos com as famílias de origem de cada um dos cônjuges.

Freqüentemente o início de um novo núcleo familiar e a construção da conjugalidade são demarcados por uma cerimônia de casamento civil e/ou religioso. É a partir desta celebração que os indivíduos assumem os papéis e as funções de marido e mulher perante a sociedade. Zordan et al. $(2005)^{1}$ descrevem seu entendimento a respeito

\footnotetext{
* Este artigo é baseado na Tese de Doutorado de Clarissa Corrêa Menezes, orientada pela professora Dra. Rita de Cássia Sobreira Lopes, intitulada "A transição para o Casamento" e defendida em 05 de maio de 2006 no Departamento de Psicologia do Desenvolvimento Humano do Instituto de Psicologia da UFRGS (Universidade Federal do Rio Grande do Sul).

**ccmenezes@terra.com.cr
} 
dos significados que estão implícitos nesta definição de casamento. Para as autoras, o conceito de casamento deixa expresso o caráter solene e ritualístico do mesmo, uma vez que costuma ser festejado a partir de normas, valores e costumes sociais. Ponzetti Jr. $(2003)^{2}$, de forma semelhante, considera que a assunção dos papéis de marido e mulher tende a ser determinada a partir de uma cerimônia social de casamento e claramente indica o início de um novo núcleo familiar e a emergência de uma nova geração. Para o autor, os casamentos tendem a ser demarcados por rituais e se constituem em uma transição social e emocional importante para o jovem casal, uma vez que, na maior parte das sociedades, representam a passagem para a adultez e a potencial transição para a parentalidade.

Neste sentido, destaca-se um tema importante quando se pensa na transição para o casamento na atualidade: a coabitação. A coabitação é um fenômeno mundial e atual que não pode deixar de ser mencionado quando se fala em casamento e, em especial, na transição para o casamento. De acordo com estudo elaborado por Rangel (2003) $)^{3}$ a coabitação está redesenhando a vida familiar em todo o mundo e o Brasil não é uma exceção no processo de popularização da coabitação. Conforme McGinnis (2003) ${ }^{4}$, na medida em que a coabitação tem se tornado uma forma de viver cada vez mais comum, ela começa a ser considerada como um estágio da relação conjugal e passa a merecer mais destaque na literatura sobre a relação conjugal. De fato, é cada vez maior o número de casais que escolhem coabitar, como uma etapa preliminar ou como uma alternativa ao casamento ( $\mathrm{Wu} \& \mathrm{Hart}, 2002^{5}$ ) e algumas evidências mostram que os próprios coabitantes consideram a sua relação como um estágio anterior ao casamento (Bumpass et al., $1991^{6}$ ). Alguns autores consideram ainda que a coabitação tornou-se não apenas uma forma viável de constituição familiar (Wu \& Hart, 2002), mas inclusive um evento normativo do ciclo de vida dos indivíduos (Smock, 20007\% Brown, 20048).

Sobre o tema da coabitação, McGinnis (2003) e Brown (2004) relatam que há poucas pesquisas específicas e que alguns autores têm se ocupado em comparar indivíduos coabitantes e não-coabitantes ou casais coabitantes e casais casados formalmente. Neste sentido, McGinnis (2003) propôs um modelo que considera que a coabitação afeta a percepção dos custos e dos benefícios do casamento e, assim, termina por influenciar as expectativas dos indivíduos sobre o casamento e a sua intenção de casar ou não.

Quando se estuda a transição para o casamento, alguns temas se mostram centrais. Um deles é o difícil equilíbrio que os indivíduos alcançam entre as dimensões da conjugalidade e da individualidade. Ao teorizar a respeito da individualidade e da conjugalidade, Féres-Carneiro $(1998)^{9}$ conceitua estas duas dimensões da vida humana. A individualidade refere-se a tudo que diz respeito ao individuo, seus desejos, suas inserções e percepções de mundo e suas histórias e projetos de vida, ou seja, sua identidade. A conjugalidade, existente através de uma relação amorosa, seria um desejo conjunto, uma história de vida conjugal, um projeto de vida de casal, ou seja, uma identidade conjugal. A conjugalidade, segundo Féres-Carneiro e Magalhães (2000) ${ }^{10}$, seria uma estrutura composta a partir da individualidade dos membros de um casal e do interjogo dinâmico do par conjugal, ou seja, seria um eu conjugal, um sistema com funcionamento autônomo. No entendimento de Féres-Carneiro (1998), ainda, uma das características centrais da conjugalidade é a oscilação entre momentos de fusão e de diferenciação entre os membros do casal.

Outro tema que parece importante na transição para o casamento refere-se às expectativas depositadas no casamento, as quais têm um papel importante, tanto no momento da escolha do futuro cônjuge, quanto no do estabelecimento da relação conjugal propriamente dita. Desta forma, em nossa cultura, há uma visão romântica do casamento. Este é considerado como meio de libertação e de felicidade total. O indivíduo idealiza que o outro será o responsável pela realização de seus desejos e pela compensação de suas carências. A escolha conjugal costuma ser motivada, segundo Anton (2000) ${ }^{11}$, pela necessidade de satisfação de desejos e instintos, através da relação com objetos simbólicos. Esta eleição está baseada na percepção inconsciente de que o objeto é capaz de exercer o papel que lhe atribui o sujeito. Whitaker $(1990)^{12}$, 
anteriormente, havia desenvolvido sua teoria de que toda união conjugal tem início com a crença ilusória, de cada um dos membros, de tornar-se um todo e ser satisfeito de forma completa em suas necessidades. Como conseqüência da percepção de que a realidade é distinta desta ilusão, o autor indica que deve haver o desenvolvimento do casal no sentido de que cada um possa ir além do "eu" e do "ele" ou "ela", em direção à construção do "nós". Quando há a busca pelo "nós", há a possibilidade de êxito e de sucesso na relação conjugal.

Brown (2003), em sua pesquisa a respeito do papel do casamento em casais coabitantes, realizou uma revisão acerca das principais motivações que levam os casais coabitantes a formalizarem sua relação através do casamento. Em coabitantes, uma das motivações para o casamento é a expectativa de que este aumente sua segurança emocional e econômica, assim como sua felicidade em geral. Além disso, coabitantes esperam melhorar sua vida sexual e a qualidade de seu relacionamento conjugal com o casamento. Brown sintetiza outros fatores centrais que podem motivar coabitantes a formalizarem sua união através do casamento: (1) aumentar o comprometimento e a estabilidade da relação; (2) o desejo de estar casado e a percepção de que o casamento fornece um status de adulto perante a sociedade; (3) a pressão familiar para que se casem (ou porque seus pais gostariam que casassem ou porque os coabitantes planejam ter filhos e gostariam de legitimar o nascimento dos mesmos); e, finalmente, (4) as expectativas normativas relacionadas ao casamento, tais como definição clara de papéis de marido e mulher e os benefícios que esta definição provê.

Por fim, o terceiro tema que se mostra central no estudo e na compreensão da transição para o casamento é referente à influência que as famílias de origem têm na construção de expectativas e na forma de os indivíduos se relacionarem como casal. Carter e McGoldrick (1995) ${ }^{13}$ acreditam que os mitos e as atitudes sobre família e casamento são passados de geração para geração. Investigando o grau de influência que os modelos parentais teriam na escolha conjugal, Gehar $(1997)^{14}$ pesquisou as similaridades em caracte- rísticas de personalidade apresentadas entre parceiros e pais e confirmou sua hipótese para metade das características analisadas. Os próprios sujeitos, no entanto, percebiam seus parceiros como similares a seus pais do sexo oposto no que se referia a todos os fatores analisados, assim como apontaram congruência entre a personalidade de seus pais e a idéia que faziam de seus pares ideais.

Alguns autores consideram que o estabelecimento das fronteiras dos novos casais, tanto entre o casal e suas famílias, quanto entre os membros do casal em si, seria uma tarefa crítica durante a transição para o casamento. Carter e McGoldrick (1995) consideram que dentro de cada sistema familiar existe a necessidade de que as diferentes gerações se acomodem, simultaneamente, às transições do ciclo de vida, à mistura de gerações e a sua influência nos relacionamentos e nas interações entre os indivíduos. Este entendimento apóia o de Bowen (1978) $)^{15}$, que desenvolveu o conceito de diferenciação do eu e que postulava que o nível de diferenciação da família que os indivíduos adquirem é transmitido pela própria família de origem. Para o autor, ainda, um nível alto de diferenciação do eu da família de origem seria necessário para o desenvolvimento de vínculos afetivos novos e saudáveis A necessidade de diferenciação do eu da família de origem também é relacionada por Bowen (1978) à necessidade do estabelecimento de alguma diferenciação quando os indivíduos propõem-se a construir e a pertencer a novos subsistemas, como é o caso de um casal que passa pela transição para o casamento.

Os recém-casados deveriam dar uma maior prioridade à relação com o cônjuge e se individuar e diferenciar de alguns vínculos próximos que possam ter estabelecido com pais e parentes em geral (Bowen, 1978; Bray, 1995 ${ }^{16}$ ) Também enfatizando a necessidade de diferenciação das famílias de origem, Holman e Li (1997) ${ }^{18}$ consideram como importantes, em sua avaliação sobre a prontidão para o casamento, aspectos tais como a diferenciação emocional do casal de seus pais, seu preparo para a exclusividade sexual, e seu desejo de assumir responsabilidade em uma relação.

Também o papel da aprovação dos pais e dos pares em relação ao cônjuge escolhido tem sido investigado. De acordo com Cate e Lloyd 
$(1992)^{19}$ e Holman et al. (1994) $)^{20}$ o apoio ou a benção dos pais ao casamento foi considerado importante e de valor para os indivíduos pesquisados, mesmo depois de estes terem deixado a casa dos pais e estarem vivendo por si sós, na construção de sua própria identidade.

A relevância da relação de casal na forma como cada família se desenvolve já fora apontada por nós no relato de investigação acerca da relação conjugal na transição para a parentalidade. Neste estudo, concluímos apontando para o papel preponderante da qualidade da relação conjugal estabelecida por cada casal na forma como passam pela transição para a parentalidade, a qual é demarcada pelo nascimento do primogênito (Menezes, 2001) ${ }^{21}$.

A partir do entendimento de que toda família segue um ciclo de vida e, desta maneira, é originada através da união de dois indivíduos como um casal, pode-se considerar que a transição para o casamento tem um papel importante na forma como cada casal e, conseqüentemente, cada família vai se desenvolver posteriormente.

Em função da relevância deste tema, do pequeno volume de trabalhos acerca do mesmo, uma vez que é um tema de interesse recente, e com a intenção de dar continuidade aos apontamentos realizados por mim em minha investigação acerca da relação conjugal na transição para a parentalidade, o presente estudo tem o objetivo de analisar como os casais coabitantes e os casais não coabitantes passam pela transição para o casamento.

\section{MÉTODO}

\section{Participantes}

Participaram deste estudo quatro casais que não tinham filhos e que estavam prestes a realizar o seu primeiro casamento num período de, aproximadamente, seis meses da data do recrutamento. Destes quatro casais, dois nunca haviam morado juntos antes do casamento e dois já haviam coabitado antes do casamento por um período de, no mínimo, um ano e meio. Os casais foram selecionados em grupos de preparação para noivos.
O casal 1, que nunca havia morado junto, era composto por Aline, 26 anos de idade e cursando doutorado e por Jonas, 32 anos de idade curso superior completo. O Casal 2, que também nunca havia morado junto, era composto por Fabiana, 26 anos de idade, curso superior incompleto e por Emerson, 30 anos de idade e completando o nível superior. O casal 3, coabitante, era composto por Vânia, de 26 anos de idade e curso superior incompleto e por Lúcio, de 25 anos, que estava cursando o nível superior. O casal 4, coabitante também, era composto por Paula, 32 anos de idade e curso superior completo e por César, 29 anos e que estava completando o curso superior.

\section{Delineamento e Procedimentos}

Trata-se de um estudo qualitativo e longitudinal, abrangendo as seguintes quatro etapas da transição para o casamento: o último semestre antes do casamento e o primeiro, o sexto e o décimo-segundo mês de casamento. Foi realizado um estudo de caso coletivo, definido por Stake $(1994)^{22}$ como aquele em que se acredita que um conjunto de casos, semelhantes ou distintos, possibilitará o conhecimento mais profundo sobre um determinado fenômeno. Na presente investigação, objetivou-se explorar e conhecer as principais temáticas com relação à vivência de casais coabitantes e de casais não-coabitantes no período de transição para o casamento.

Os procedimentos realizados foram comuns a todos os casos considerados. Cada casal foi contatado através de cursos para casais, realizados como exigência para o casamento na religião católica, ou através de indicação. Todos foram convidados a participar da pesquisa e, ao aceitarem, preencheram a Ficha de Dados Demográficos de cada um dos Futuros Cônjuges. Durante o último semestre antes da cerimônia do casamento, cada casal foi convidado a assinar o Consentimento Livre e Esclarecido. Neste mesmo momento, cada um dos indivíduos, separadamente, foi entrevistado a partir da Entrevista Individual com cada Futuro Cônjuge no Último Semestre antes do Casamento.

Após um mês da data do casamento, foi realizado contato novamente com os casais, a fim 
de realizar a segunda etapa da pesquisa, que consiste em uma entrevista individual com cada um dos cônjuges a partir da Entrevista com cada Cônjuge no Primeiro Mês de Casamento. O mesmo procedimento foi realizado no sexto e no décimosegundo mês de casamento com cada díade. Nestes momentos, as estruturas das entrevistas foram semelhantes às das entrevistas do primeiro mês de casamento, mas adaptadas ao período correspondente.

\section{Instrumentos}

Nesta pesquisa utilizaram-se entrevistas semi-estruturadas com cada individuo, separadamente, em cada momento considerado da transição para o casamento. Na primeira fase do estudo, foram utilizadas:

- Ficha de Dados Demográficos de cada um dos Futuros Cônjuges

- Entrevista Individual com cada Futuro Cônjuge no Último Semestre antes do Casamento: abrangendo aspectos como a história da relação, a decisão de casar, a individualidade e a conjugalidade, o significado, as motivações e as expectativas sobre o casamento e a participação das famílias de origem.

Na segunda fase da pesquisa, foi utilizada:

- Entrevista com cada Cônjuge no Primeiro Mês de Casamento: aspectos como a individualidade e a conjugalidade, o significado, as motivações e as expectativas sobre o casamento e a participação das famílias de origem.

Na terceira fase da pesquisa:

- Entrevista com cada Cônjuge no Sexto Mês de Casamento: a individualidade e a conjugalidade, o significado, as motivações e as expectativas sobre o casamento e a participação das famílias de origem.

Por fim, na quarta fase da pesquisa:

- Entrevista com cada Cônjuge no Décimo Segundo Mês de Casamento: a individualidade e a conjugalidade, o significado, as motivações e as expectativas sobre o casamento e a participação das famílias de origem.

\section{RESULTADOS E DISCUSSÃO}

Esta pesquisa se caracterizou por ser um estudo de caso coletivo (Stake, 1994). As entrevistas realizadas com cada um dos indivíduos dos quatro casais foram analisadas a partir de análise qualitativa de conteúdo (Laville \& Dionne, 1999) ${ }^{23}$. Segundo Laville e Dionne (1999), na analise qualitativa de conteúdo o pesquisador pode e opta por se prender às nuances de sentido existentes nos dados e aos elos lógicos entre as categorias consideradas, visto que a significação de um conteúdo reside na especificidade de cada um de seus elementos e nas relações entre eles, o que escapa, muitas vezes, ao domínio do mensurável. Neste estudo, a analise foi baseada qualitativa de conteúdo foi baseada nas seguintes categorias temáticas pré-estabelecidas: a individualidade e a conjugalidade; o casamento e a avaliação sobre a própria relação de casal; e a relação com as famílias de origem. Desta forma, a seguir são apresentados, através de alguns exemplos, e discutidos os resultados referentes a cada uma destas categorias. Por fim, os principais achados e as reflexões centrais deste estudo são apresentados nas considerações finais.

\section{A individualidade e a conjugalidade}

Os resultados deste estudo revelaram que a temática da administração da conjugalidade e da individualidade não mostrou um padrão específico entre casais coabitantes ou não coabitantes antes de casar. Os casais 2 (não-coabitante) e 3 (coabitante) deram maior ênfase na sua conjugalidade ao longo da transição para o casamento. Esta ênfase pode ser exemplificada a partir das seguintes falas do caso 2: "a gente quer sempre estar junto um do outro (...) a gente é parceiro pra tudo" (noivo aos seis meses de casamento); "a relação tá boa demais, eu tô me tornando muito dependente dele..." (noiva antes do casamento) e "a gente procura fazer tudo junto, desde ir na feira, ir na farmácia, acho que até levar o lixo. Estamos sempre juntos" (noiva aos doze meses de casamento). No caso 3, as seguintes falas exemplificam a ênfase dada na conjugalidade: “... não tem muita coisa que a 
gente faça separados.. . a maioria das coisas que a gente faz a gente faz junto" (noivo antes do casamento) e "...até que ponto isso (individualidade) é importante? Até que ponto é normal? Entendeu? Que isso é muito delicado, porque, assim, a maioria das pessoas não sabe até onde isso vai, até onde isso é normal, entendeu? Porque, se tu começa a te tornar tão individual, que tu acaba esquecendo do teu companheiro, da tua companheira, entendeu? Então eu acho que a maioria das pessoas que têm problemas no casamento eu acho que eles tão vendo muito mais o individual do que o nós, entendeu?" (noiva aos seis meses de casamento).

Por outro lado, os casais 1 (não-coabitante) e 4 (coabitante) privilegiaram a individualidade em todos os momentos, o que fica evidente nas seguintes falas do caso 1: “... a gente prioriza muito pouco o casal. A nossa prioridade é o trabalho, então a gente se vê tri pouco (...) eu acho [que um bom casamento] tem que ter autonomia dos dois, lberdade, né, respeito..." e (noivo aos doze meses de casamento) e "[juntos] apenas limpamos a casa, é a única coisa que a gente faz junto...” (noiva no primeiro mês de casamento). No caso 4 , as seguintes falas exemplificam a ênfase na individualidade: "a vida social [individual] a gente preservou sempre, desde o inicio até agora, ne, e respeitando cada um com seus amigos, ne, sair com liberdade, né?" (noivo antes do casamento); "[atividades juntos] de modo geral, sempre com os amigos..." (noiva no primeiro mês de casamento) e "[juntos] mais é sair com os amigos (...) [separados] eu continuo saindo com as minhas amigas quando dá e ele também... a gente nunca se questionou isso 'ah, tu vai sair e eu não" (noiva aos doze meses de casamento).

Assim, o que percebemos foram duas tendências relevantes com relação a este tema. Uma delas diz respeito à tendência de os casais manterem-se polarizados com relação a privilegiar a individualidade ou a conjugalidade, sendo que o almejado equilíbrio entre conjugalidade e individualidade se mostrou difícil de ser atingido durante o período avaliado. Além desta polarização, percebemos uma tendência à estabilidade nos casais quanto a esta polarização na conjugalidade ou na individualidade.
A partir destes achados, questionamo-nos se a polarização e a estabilidade são tendências comuns ao período da transição para o casamento. Como consideram Carter e McGoldrick (1995) este período é um "ponto de transição do ciclo da vida familiar" e um período de "crise", o qual pode gerar um aumento do estresse e da ansiedade vividos pelos indivíduos. Para os autores que estudam as famílias, toda crise provoca uma ruptura temporária da homeostase do sistema familiar e, conseqüentemente, a necessidade de reorganização das relações e de construção de novas regras de funcionamento familiar. Neste sentido, podemos pensar que a tendência à polarização e à estabilidade, na transição para o casamento, seria uma tentativa de evitar a transformação e de manter, tanto quanto possível, a homeostase do sistema conjugal. Segundo Nichols e Schwartz $(1998)^{24}$, homeostase e transformação são os processos básicos de manutenção do sistema familiar e podem ocorrer para promover o desenvolvimento funcional ou disfuncional das famílias. Se os membros de um casal, por exemplo, precisam passar por transformações em suas relações, pois estão oficializando socialmente sua união, mas tendem a evitar as mudanças advindas deste novo estágio de suas vidas, feedbacks negativos serão utilizados com a função de manter a homeostase do sistema.

Ainda a partir do entendimento de que há um ciclo de vida familiar, Carter e McGoldrick (1995) apontam que nos momentos de transição do sistema familiar, no qual se enquadraria o de transição para o casamento, foco do presente estudo, costuma ocorrer também um aumento do estresse vivido pelos indivíduos. As fontes de estresse podem ser "horizontais" e "verticais". As influências "horizontais" são as relacionadas ao desenvolvimento do sistema familiar, conforme este avança no tempo e é levado a lidar com as mudanças e transições do seu ciclo de vida. As influências "verticais", por outro lado, incluem os padrões de relacionamento e funcionamento que são transmitidos transgeracionalmente, através das relações estabelecidas com as famílias de origem.

Também baseada no conceito de ciclo de vida, uma outra perspectiva que poderia auxiliar a compreensão da tendência à polarização e à 
estabilidade vivenciada pelos casais desta pesquisa é a apontada por Pittman (1994) ${ }^{25}$ quando apresenta sua idéia de que há um ciclo de vida dos casais. Assim como as famílias passam por um ciclo de vida, também os casais teriam um ciclo de vida próprio. Acreditamos que os casais estudados na presente investigação estão vivenciando as questões referentes ou à primeira ou à segunda etapas apontadas pelo autor. A primeira etapa foi denominada por Pittman (1994) de enamoramento e se caracteriza pelo desejo mútuo e compartilhado dos indivíduos de se tornar apenas um. Nesta etapa se enquadrariam os casais que vivenciaram de forma polarizada e estável a conjugalidade. Neste momento, não há espaço para as diferenças individuais e, freqüentemente, estabelece-se um estado de fusão em que o casal passa a criar um sentido único de percepção do mundo externo. A segunda etapa apresentada por Pittman (1994) é intitulada estabelecendo diferenças e se refere ao momento em que os cônjuges começam a pensar de forma distinta e as diferenças individuais tornam-se visíveis. Acreditamos que os casais que tenderam a privilegiar a individualidade de forma polarizada e estável durante a transição para o casamento estariam ou vivenciando a segunda etapa ou se protegendo contra a vivência da primeira, da fusão, que para alguns indivíduos é muito ameaçadora.

\section{O casamento e a avaliação sobre a própria relação de casal}

No que se refere à avaliação da própria relação de casal e à cerimônia de casamento observamos que um tema foi comum aos quatro casais: a importância atribuída ao romantismo na vida dos mesmos. Alguns exemplos estão nas falas a seguir: "o ponto fraco da nossa relação é a falta de romantismo" (caso 1, noivo antes do casamento); "todo o tempo que a gente tem a gente quer ficar junto, um perto do outro" (caso 2, noivo antes do casamento); "[o ponto forte da relação] é a parceria que a gente tem, tanto dentro da cama, quanto fora dela, né, nós somos parceiros, o fato de a gente querer estar sempre junto um do outro, estar perto do outro..." (caso 2, noivo no primeiro mês de casamento); "[a relação] está boa demais e eu to me tornando muito dependente dele, então eu acho, assim, que eu tenho medo, eu já falei pra ele, eu tenho medo de estar sonhando, acordar e cair da cama e, quando ver, acabou... tudo é ponto forte, porque aquele tempo que a gente tá junto, a gente vive aquele momento é intenso pra nós, como se fosse o único sabe" (caso 2, noiva antes do casamento); "[um bom casamento] é baseado em muita conversa, muito respeito, muito companheirismo, assim, sabe, e em amor, né, porque, se tu não tiver amor, se tu não gostar, sabe, se tu não tiver aquele sentimento, assim, sabe, ai tu pode ter todas aquelas qualidades que eu te disse, mas sem amor, tu acaba tendo só uma amizade..." (caso 3 , noiva no primeiro mês de casamento); “ $a$ relação está cada vez mais forte (...) a gente tem uma ligação muito forte um com o outro, uma preocupação..." (caso 4, noivo antes do casamento); e " [os pontos fortes da relação são] fidelidade, respeito, carinho, muito carinho, companheirismo. Eu acho que eu definiria assim, claro, eu defino tudo isso, eu nunca falo a palavra amor, porque eu defino o amor como tudo isso, né, não defino amor como uma paixão, que logo passa. Então, pra mim, a definição de amor é isso, a gente se ama em função de haver tudo isso" (caso 4, noiva antes do casamento). O destaque dado ao romantismo parece-nos fazer sentido, uma vez que a transição para o casamento é justamente o momento em que a relação de casal pode ser consolidada. Para muitos casais, o romantismo é o ingrediente essencial que os mantém unidos, mesmo sendo confrontados com as necessárias adaptações deste período. A capacidade de manter e cultivar o romantismo ficou mais evidente justamente nos dois casais que mostraram dar maior ênfase na conjugalidade.

Diferentemente do que ocorreu nos temais temas levantados, alguns aspectos referentes à avaliação da própria relação e à cerimônia de casamento mostraram uma tendência a ter um padrão específico entre os casais coabitantes e os não coabitantes. No que diz respeito à diferença observada entre os casais que coabitavam e os que não coabitavam antes de casar, com relação à avaliação do próprio relacionamento, percebemos que os casais coabitantes mencionaram a 
coabitação como tendo auxiliado na preparação para o casamento. Algumas falas que exemplificam este entendimento são as seguintes: " $[a$ decisão de casar] veio por estarmos morando junto, né, porque, com é que eu vou te dizer (...) uma das coisas que levou, na verdade, a gente a casar foi, digamos, o test drive que a gente fez antes de casar, né, que foi eu ter vindo morar aqui, a gente ter convivido esse tempo junto antes de casar e ter visto que a gente dava certo, assim..." (casal 3, noivo antes do casamento); e "[a decisão de casar foi porque] assim, a gente começou a conviver, o que eu vou te dizer, assim ó, o tratamento dele comigo, o respeito, em primeiro lugar, né (...) o carinho, muito carinhoso, respeito, uma pessoa super educada..." (casal 4, noiva antes do casamento). Assim, nos casais coabitantes o casamento esteve relacionado a uma avaliação positiva da qualidade da relação, como uma conseqüência desta, o que fica evidente nos exemplos anteriores.

Nos casais que não coabitavam antes de casar, outra peculiaridade foi evidenciada. Para estes, a visão sobre um bom e um mau casamento se alterou, em função das vivências práticas que estabeleceram em cada momento da transição para o casamento, como se pode perceber a partir de alguns exemplos a seguir. No caso 1, antes do casamento, a noiva descreveu um bom casamento "respeito, acho que dividir tarefas já é um sinal de respeito" enquanto aos doze meses de casamento ela descreveu um bom casamento como o que tem "companheirismo e fidelidade, tu poder confiar...". No caso 2, antes do casamento, a noiva descreveu um mau casamento como sendo aquele em que "cada um tenta invadir os limites do outro (...) aquele que ainda tem a figura da mulher como uma empregada de casa, como uma escrava, entendeu?" enquanto aos seis meses de casamento descreveu um mau casamento como aquele "onde rola mentira, sabe, eu digo pra ele, tu não me mente nem me omite né (...) aonde a gente começar com mentira ou discórdia, muita coisa (...) isso aí vai afundando cada vez mais a relação...”.

A alteração dos conceitos sobre um bom e um mau casamento não ocorreu com os casais coabitantes, que pareciam já ter estabelecido alguns conceitos mais estáveis sobre o casamento, em função de terem vivenciado o mesmo, de certa forma, através da coabitação anterior. Nesses casais, é interessante que são utilizadas as mesmas palavras para descrever um bom e um mau casamento antes dos respectivos casamentos e nos períodos posteriores aos mesmos.

Parece-nos que as diferenças encontradas entre os casais que coabitavam e os casais que não coabitavam antes de casar, no que se refere à avaliação da própria relação, nos indicam que a coabitação é vista como uma etapa anterior ao casamento e mais avançada que o namoro ou noivado. Este entendimento é coerente com os apontamentos de McGinnis (2003), que acredita que, uma vez que a coabitação tem se tornado uma forma de viver cada vez mais comum, ela deve ser considerada como um estágio da relação conjugal e do ciclo de vida dos casais. Segundo Wu e Hart (2002), muitos casais têm escolhido coabitar como uma etapa preliminar ao casamento, e algumas evidências mostram que os próprios coabitantes consideram a sua relação como um estágio anterior ao casamento. Assim sendo, acreditamos que a coabitação está se tornando um evento normativo do ciclo de vida dos casais e que, como uma etapa anterior ao casamento, possibilita um preparo e a construção de expectativas menos idealizadas sobre o casamento.

$\mathrm{O}$ fato de a coabitação propiciar um maior preparo para os casais com relação às vivências do casamento também pode ser explicado pelo achado deste estudo que revelou que, apenas nos casais que já coabitavam, ficou explícita a relação que era estabelecida entre o casamento e a potencial transição para a parentalidade. A relação entre a formalização do casamento e o planejamento do primeiro filho foi apontada por nós recentemente em um estudo que explicitou a existência de uma associação significativa entre a formalização do casamento e o planejamento da gravidez do primeiro filho (Lopes, Menezes, Santos \& Piccinini, 2006) ${ }^{26}$. Assim, tal pesquisa demonstrou que a oficialização do casamento claramente demarca o início de um novo núcleo familiar, a passagem para a adultez e, também, a potencial transição para a parentalidade. É interessante retomar que, embora nesta investigação de douto- 
rado todos os casais tenham passado pela oficialização do casamento, apenas os coabitantes mencionaram a potencial parentalidade. A transição para a parentalidade representaria a etapa seguinte do ciclo de vida de uma família. Acreditamos que, como os casais coabitantes já haviam vivido o que eles mesmos denominam de "um estágio anterior ao casamento" e, desta forma, se preparado para o casamento, mostraram-se mais prontos para começar a pensar no próximo estágio, o da transição para a parentalidade.

\section{A relação com as famílias de origem}

No que se refere à relação com as famílias de origem, os resultados também não revelaram um padrão específico entre os casais coabitantes e os não coabitantes, sendo que as principais temáticas levantadas pelos casais mostraram-se estáveis ao longo dos momentos considerados da transição para o casamento. O tema que predominou em todos os casais considerados foi referente ao fato de os pais serem, sempre, uma referência de como se relacionar com alguém, para alguns uma referência de como fazer igual e, para outros, de como fazer o contrário. Essa referência positiva ficou explicita nas falas de alguns participantes, como no seguinte relato da noiva do casal 1, no momento anterior ao casamento: "é, meu pai é falecido há 10 anos, mas eu tenho muito forte isso assim, do casamento deles, acho que era um modelo, modelo mesmo... eles se gostavam, se adoravam...". Já neste relato do noivo do casal 2 antes do seu casamento pode-se perceber a referência negativa que os pais foram como casal: "eles [seus pais] tão acostumados um com o outro, vivem na deles assim, cada um na sua e não me servem como modelo. Eu acho que tem que ter mais amor, carinho, mais afeto, entre o casal (...) não me servem como exemplo, até servem como exemplo assim de como fazer o contrário, né, é um bom espelhamento nesse ponto...".

A importância que os pais assumem na vida dos indivíduos, não apenas por serem os primeiros a estabelecer relações de amor com os mesmos, mas também por serem um modelo de "como ser um casal" nos pareceu muito interessante e pertinente ao enfoque teórico adotado, o familiar sistêmico.

Outro tema que se salientou nos casais estudados, com relação às famílias de origem, foi o da necessidade de diferenciação das mesmas. Algumas falas evidenciam esta necessidade, como o seguinte relato do noivo do casal 4: "[o tema que mais gera conflitos no casal] é mais sobre a mãe dela, assim, que a gente tem, as vezes, uns atritos, só que eu fico estressado às vezes (...) eu me estresso porque são coisas que a mãe dela fala demais que eu não gosto de ouvir...”. Também a fala da noiva do casal 1 expressa tal necessidade de diferenciação das famílias de origem: “[a relação com os pais do noivo] está mais tranqüila (...) eles vinham aqui, esperavam alguma coisa chegar pra nós, eles ajudavam muito e até demais na minha opinião. Teve uma época que eu me estressei com isso, porque era demais...". O conceito de diferenciação do eu foi desenvolvido por Bowen (1978), que acreditava que o nível de diferenciação da família que os indivíduos adquirem é transmitido pela própria família de origem. Para o autor, ainda, um nível alto de diferenciação do eu da família de origem seria necessário para o desenvolvimento de vínculos afetivos novos e saudáveis. É interessante que os casais deste estudo mencionaram, espontaneamente, tal necessidade no momento em que passavam pela transição para o casamento.

A necessidade de diferenciação do eu da família de origem também é relacionada por Bowen (1978) à necessidade do estabelecimento de alguma diferenciação quando os indivíduos propõem-se a construir e a pertencer a novos subsistemas, como é o caso de um casal que passa pela transição para o casamento. A necessidade de estabelecer algumas fronteiras entre o novo casal e as famílias de origem foi também trabalhada por Minuchin (1982) ${ }^{27}$. Para este autor, as fronteiras seriam as regras que definem quem participa e como de cada subsistema, com o objetivo de proteger a diferenciação dos mesmos. No momento da transição para o casamento, em que um novo sistema conjugal começa a se constituir, é natural que a necessidade de novas fronteiras e de uma diferenciação das famílias de origem seja reivindicada, como ocorreu nos casos estudados. 


\section{CONSIDERAÇÕES FINAIS}

Acreditamos que este estudo pôde abranger e aprofundar as questões inicialmente propostas. Através de delineamento longitudinal, pudemos acompanhar os casais estudados ao longo do período de um ano e meio de suas vidas, período em que as transformações vividas pelos mesmos puderam ser observadas e compreendidas. Além disso, destacamos os conceitos de ciclo de vida familiar e de ciclo de vida do casal, corroborados por este estudo através da tendência apontada pelos resultados à polarização e à estabilidade nos momentos de transição de um estágio para outro. Finalmente, ressaltamos a abordagem e o aprofundamento acerca do tema da coabitação, que se mostrou bastante atual e relevante, mas ainda pouco investigado na área.

Apesar disto, algumas temáticas que emergiram ao longo da realização do estudo pareceram da também importantes, mas não puderam ser abordadas no mesmo. Um tema que não foi por nós aprofundado, mas que merece atenção em futuras investigações, é a sexualidade durante a transição para o casamento. Nos dias atuais, a vida sexual dos indivíduos é iniciada muito mais precocemente do que no passado. Desta forma, muitos dos casais que casam, atualmente, já vivem sua sexualidade de forma plena. Certamente, o tema da sexualidade mostra-se importante e o casamento pode ter algumas repercussões importantes.

Outra temática que nos parece importante, mas que também não pôde ser abordada com profundidade neste trabalho, refere-se à rede social mais ampla, que vai além das relações familiares consangüíneas. Atualmente, muitos dos jovens que se casam têm um grupo de amigos já estabelecido e como administram tais amizades na transição para o casamento parece ser um tema relevante.

A questão da organização da casa e da administração das finanças também se mostra um tema relevante que não pôde ser abrangido de forma aprofundada neste estudo.

Desta forma, seria interessante e necessário propor novos estudos que pudessem abarcar estas temáticas no período da transição para o casamento. Uma das principais temáticas que acreditamos que deveria ser estudada e aprofundada é a da tendência encontrada à polarização e à estabilidade no que se refere à individualidade e a conjugalidade e às relações com as famílias de origem. Também acreditamos que seria muito enriquecedor seguir acompanhando estes casais ao longo das próximas transições que serão por eles vividas. Este é um projeto ao qual pretendemos dar seguimento e representa a possibilidade de acompanhar os casais, desde sua formação, na vivência das etapas posteriores do seu ciclo de vida familiar. Neste sentido, acreditamos que seria especialmente interessante acompanhar estes casais em sua transição para a parentalidade, etapa seguinte do ciclo de vida familiar, considerando-se sua tendência a dar maior ênfase na individualidade ou na conjugalidade.

Finalmente, destacamos as possíveis contribuições dos achados desta investigação. Através de delineamento longitudinal, pudemos acompanhar os casais estudados ao longo do período de um ano e meio de suas vidas. As eventuais modificações e transformações vividas pelos mesmos puderam ser observadas no momento em que ocorriam e a partir do próprio relato dos indivíduos que a vivenciavam, o que representa um aspecto valioso na construção de estudos de casos e no desenvolvimento do conhecimento cientifico. Além disso, o fato de termos entrevistado individualmente cada cônjuge, em cada momento considerado, permitiu que tivéssemos contato com as visões de cada um sobre o casamento e sobre as temáticas abordadas. Abriu-se, assim, espaço para que aparecessem questões polêmicas e de insatisfação, as quais não costumam aparecer com tanta facilidade em entrevistas conjuntas.

Além disso, o tema abordado - a transição para o casamento em casais coabitantes e em casais não coabitantes - mostrou-se muito relevante e pode ser um fator enriquecedor na compreensão das estruturas familiares. Acreditamos que tanto as pesquisas científicas sobre casais e famílias, quando a clínica de terapia de casais e famílias se beneficiarão dos achados aqui destacados.

Finalmente, destacamos que os achados deste estudo corroboram o entendimento de que há um ciclo de vida da família e do casal, que se coadunam ao entendimento sistêmico de tendência 
à homeostase e à transformação, sendo importante identificar como cada casal se situa nesta etapa de transição do ciclo de vida. Além disso, cabe considerar a coabitação, cada vez mais freqüente na contemporaneidade, como um possível estágio da relação conjugal e do ciclo de vida dos casais.

\begin{abstract}
This study aimed to analyze the way cohabitant and non cohabitant couples go trough the transition to marriage, from the previous semester up to the end of the first year after the marriage. The participants were four adult couples, two cohabitants and two no-cohabitants. The interviews with each participants were analyzed through qualitative content analysis, which generated some thematic axes: the individuality and the conjugality, the the wedding ceremony and the evaluation of the relationship; and the relationship with the family of origin. The results revealed that there was a trend towards polarization and stability in what refers to the individuality and the conjugality and to the relationship with the families of origin and that there were no difference between the cohabitant and the non cohabitant couples in these aspects. As far as the evaluation of the relationship and of the wedding ceremony is concerned, some differences were found between cohabitants and non cohabitants.
\end{abstract}

Key words: Marriage. Cohabitants. Non cohabitants. Conjugality. Individuality.

\title{
REFER $\hat{E} N C I A S$
}

1. Zordan EP, Falcke D, Wagner A. Copiar ou (re) criar? Perspectivas histórico-contextuais do casamento. In Wagner, A. (Org.). Como se Perpetua a Família? A transmissão dos modelos familiares. Porto Alegre: Edipucrs; 2005. p. 47-65.

2. Ponzetti Jr. Marriage Ceremonies. In: Ponzetti Jr. (Org.). International Encyclopedia of Marriage and Family. Nova York: Thomson Gale; 2003. p.1091-1094.

3. Rangel MA. Marriage, cohabition, and intrahousehold bargainings: evidence from brazilian couples. In: Northeastern Universities Development Consortium Conference (NEUDOC); 2003 Out; New Heaven, USA.

4. McGinnis SL. Cohabitating, dating, and perceived costs of marriage: A model of marriage entry. Journal of Marriage and the Family 2003; 65(1):105-116.

5. Wu Z, Hart R. The effects of marital and nonmarital union transition on health. Journal of Marriage and Family 2002; 64(2): 420-432.

6. Bumpass LL, Sweet JA, Cherlin AJ. The role of cohabitation in declining rates of marriage. Journal of Marriage and the Family 1991; 53: 913-027.

7. Smock PJ. Cohabitation in the United States: An appraisal of research themes, findings, and implications. Annual Review of Sociology 2000; 26: 1-20.
8. Brown SL. Moving from cohabitation to marriage: effects on relationship quality. Social Science Research 2003; 33: 1-19.

9. Féres-Carneiro T. Casamento contemporâneo: o difícil convívio da individualidade com a conjugalidade. Psicologia: Reflexão e Crítica 1998; 11(2): 379-394.

10. Féres-Carneiro T, Magalhães AS. Retorno da conjugalidade sobre a subjetividade dos parceiros: uma questão para a clínica psicanalítica do casal. [serial online] 2000 [cited 2006, jan 26]. Avaiable from: http:// estadosgerais.org/historia/141.shtml

11. Anton IC. A escolha - motivações inconscientes - do cônjuge. Porto Alegre: Sagra-dc Luzzatto; 2000

12. Whitaker A. Dançando com a família. Porto Alegre: Artes Médicas; 1990.

13. Carter B, McGoldrick M. As mudanças no ciclo de vida familiar (M. A. Veronese, Trad.). Porto Alegre: Artes Médicas; 1995.

14. Gehar G. The effects of actual and perceived parental characteristics on partner selection and perception. Dissertation Abstracts International: Section-B: The-Sciences and Engineering [periódico online]. 1997 [acesso em Jan 2006]; 58(4-B), 2178.

15. Bowen M. De la familia al individuo: la diferenciación del si mismo en el sistema familiar. Barcelona: Paidós; 1978.

16. Bray JH. Family assessment: Current issues in evaluating families. Family Relations: Journal 
of Applied Family and Child Studies 1995; 44(4): 469-477.

17. Mace D. Three ways of helping married couples. Journal of Marriage and Family Therapy 1989; 13: 179-185.

18. Holman TB, Li BD. Premarital factors influencing perceived readiness for marriage. Journal of Family Issues 1997; 18(2): 124-144.

19. Cate RM, Lloyd SA. Courtship. Thousand Oaks: Sage Publications, 1992.

20. Holman TB, Larson JH Harmer SL. The development and predictive validity of a new premarital assessment instrument: the preparation for marriage questionnaire. Family Relations 1994; 43: 46-52.

21. Menezes CC. A relação conjugal na transição para a parentalidade: Da gestação ao segundo ano de vida do bebê [dissertação]. Porto Alegre (RS): Instituto de Psicologia da Universidade Federal do Rio Grande do Sul; 2001.
22. Stake RE. Case Studies. In Denzin \& Lincoln. Handboock of Qualitative Research. Londres: Sage, 1994.

23. Lavilla C, Dionne J. A construção do saber: Manual de metodologia da pesquisa em ciências humanas. Porto Alegre: Artes Médicas, 1999.

24. Nichols M, Scwartz R. Terapia Familiar: conceitos e métodos. (M. F. Lopes, Trad.). Porto Alegre: Artmed, 1998.

25. Pittman F. Mentiras Privadas. Porto Alegre: Artes Médicas, 1994.

26. Lopes RCS, Piccinini CA, Menezes CC \& Santos G. Ritual de casamento e planejamento do primeiro filho. Psicologia em Estudo, 2006: 11(1): 55-61.

27. Minuchin S. Famílias: Funcionamento e Tratamento. Porto Alegre: Artes Médicas, 1982. 